http://dx.doi.org/10.18232/alhe.915

Artículos

\title{
El patrón oro y la Gran Depresión en Chile: 1925-1935
}

\section{The Gold Standard and the Great Depression in Chile: 1925-1935}

\author{
César Duarte ${ }^{1,}$ * iD 0000-0001-6326-6090 \\ ${ }^{1}$ Instituto de Investigaciones Dr. José María Luis Mora, Ciudad de México, México. \\ * Correspondencia: cduarte@mora.edu.mx
}

Resumen. El artículo estudia el proceso de adopción del patrón oro en Chile, su funcionamiento y las causas que llevaron a su abandono como consecuencia de los efectos de la Gran Depresión en Chile, causa fundamental del fin del patrón oro en la economía sudamericana. Con base en datos estadísticos se analizan los impactos de la crisis internacional en la economía chilena, así como en las políticas económicas implantadas. El objetivo es mostrar que la política monetaria, la cual pudo flexibilizarse por el abandono del patrón oro, tuvo un impacto mucho mayor en la recuperación de la economía chilena que la política fiscal. Esto se contrapone a la visión según la cual la adopción de políticas de corte prekeynesiano basadas en el gasto público, fueron la causa de la rápida recuperación de la crisis en la economía chilena.

Palabras clave: patrón oro; Gran Depresión; política monetaria; banco central.

Abstract. The paper studies the adoption, operation and end of the gold standard in Chile. This led to a discussion of the effects of the Great Depression in the Chilean economy, the immediate cause for the end of the gold standard. The magnitude of the impact of the international crisis and the effects of the policy measures adopted are analyzed using statistical data. The objective of the paper is to prove that monetary

CÓMO CITAR: Duarte, C. (2019). El patrón oro y la Gran Depresión en Chile: 1925-1935. America Latina en la Historia Económica, 26(2), e915. DOI: 10.18232/alhe.915

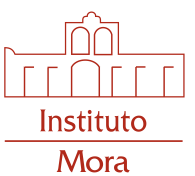


policy, which became flexible because of the end of the gold standard, had a bigger impact than fiscal policy in the overcome of the turmoil. In this way, the vision that states that the rapid recovery of the crisis in Chile can be explained by the adoption of pre-Keynesian policy measures based on public expense is questioned.

Key words: gold standard; Great Depression; monetary policy; Central Bank.

JEL: N16; N26.

Recibido: 11 de agosto de 2017.

Aceptado: 4 de octubre de 2017.

Publicado: 18 de enero de 2019.

\section{INTRODUCGIÓN}

En este texto se discute la trayectoria de la economía chilena durante el periodo de 1925 a 1935 . Esta etapa se caracterizó por distintos fenómenos, aunque el más importante fue la Gran Depresión. Sin embargo, tanto los efectos que la misma tuvo en la economía chilena como la manera en que se enfrentó estuvieron en gran medida determinados por una decisión tomada unos años antes. La instauración del patrón oro en Chile en 1925 marcaría el rumbo de su economía durante el siguiente decenio.

Los estudios sobre el impacto de la Gran Depresión en América Latina han considerado el fenómeno como un choque externo que afectó a la región a través del comercio exterior mediante el cambio en los términos de intercambio y de la balanza de pagos restringiendo el acceso al financiamiento externo (Bértola y Ocampo, 2013; Díaz, 1985; Thorp, 1984). Una vez que se analizan las causas de la recuperación el consenso es menos unánime. Algunos análisis priorizan el ejercicio de la política comercial y de balanza de pagos en la reactivación de las economías latinoamericanas. Este es el caso de Carlos Díaz-Alejandro quien identificó tres tipos de países de acuerdo con su respuesta a la crisis. Los países grandes o activos como Argentina, Brasil, Colombia y México que aplicaron políticas devaluatorias y de restricciones a las importaciones, acompañadas por una política fiscal de déficit presupuestarios inducidos por circunstancias económicas y políticas. Los países pequeños o pasivos como Honduras, Haití o la República Dominicana que esperaron la recuperación iniciada por las exportaciones. Y finalmente un grupo intermedio donde ubica a Chile y Uruguay, que rompieron con "la ortodoxia del patrón de cambio oro" (Díaz, 1985).

Para Bértola y Ocampo (2013) la recuperación en América Latina se basó principalmente en el manejo de la balanza de pagos, que tuvo una participación anticíclica mucho más importante que las políticas fiscales y monetarias de manejo de la demanda agregada, debido a que las perturbaciones macroeconómicas provenían primordialmente del exterior Bértola y Ocampo (2013). Por su parte Kindleberger (1984b) califica a la década de los años treinta en América Latina como una combinación de déficit gubernamentales, aranceles, depreciación y en algunos casos control de cambios que permitieron que la región superara los efectos del choque externo. Así, la política monetaria ha quedado supeditada a una función secundaria. Aunque Díaz (1985) reconoce la aportación de la política de crédito barato y de aumento de la oferta monetaria y termina poniendo mayor peso en el tipo de cambio y los términos de intercambio. Lo mismo ocurre con Bértola y Ocampo (2013) que, aunque reconocen que la política monetaria activa fue incluso más importante que la política fiscal para la recuperación, el manejo en la balanza de pagos fue lo más importante. 
Profundizando en el caso de la economía chilena, Palma (1988) señala que la recuperación fue impulsada por una combinación de aranceles, controles de cambio, devaluación del peso y las políticas monetaria y fiscal que califica como expansionistas. Además, considera que la orientación hacia el gasto público deficitario fue de carácter prekeynesiano. Para Marfan (1984), por otra parte, la recuperación ocurrió a partir de 1933 gracias a un aumento del gasto público financiado por un alza en los impuestos, a la desaceleración de la tasa de crecimiento del dinero, a la introducción de políticas sectoriales, y a controles en el comercio exterior. También da peso a los efectos de la expansión monetaria anterior a los años de 1933 y a la estabilidad política lograda, aunque lo más importante son los factores mencionados en primer lugar.

La política monetaria en Chile ha sido vista como uno más de los factores de la recuperación tal y como explica Palma; o como un obstáculo, ya que algunos autores consideran que el abandono del patrón oro y el posterior crecimiento de la oferta monetaria fueron causantes de una fuerte inflación que agravó los problemas y que tuvo que ser contenida para dar paso a la recuperación (Lüders y Wagner, 2003; Marfan, 1984; Riveros, 2009). En este artículo se sostiene que para el caso chileno el cambio en la política monetaria fue lo que abrió la puerta a la recuperación, y que la política fiscal tuvo una incidencia mínima ya que el gasto del gobierno se mantuvo por debajo de los ingresos, lo que permitió mantener superávit fiscales incluso en los momentos más profundos de la crisis. Los déficit fiscales que señala Palma fueron más una consecuencia de la caída en la recaudación que de un aumento en el gasto gubernamental para impulsar la demanda agregada como una manera de promover el crecimiento económico. Las políticas tradicionales se mantuvieron en el ámbito fiscal; sostenemos que fue la política monetaria la que dio flexibilidad al sistema económico chileno.

El objetivo de este trabajo es vincular este cambio en la política monetaria con el funcionamiento del patrón oro en Chile. Para ello en el primer apartado se analiza la llegada de la misión Kemmerer, encargada de proponer la reforma al sistema monetario y financiero de Chile. En el segundo apartado se estudian los efectos macroeconómicos que tuvo la instauración del patrón oro, así como las primeras consecuencias de la Gran Depresión en la economía chilena. En el tercer apartado se hace una revisión de las primeras reacciones a la crisis y las causas que obligaron al abandono del patrón oro. Posteriormente, en el cuarto apartado se presentan las políticas que permitieron alcanzar la recuperación de la economía chilena. Finalmente se presentan las conclusiones.

\section{LA MISIÓN KEMMERER}

En 1925 Chile se encontraba en medio de un periodo de alta inestabilidad política. El 9 de septiembre de 1924 Arturo Alessandri renunció a la presidencia ante la perspectiva de un golpe de estado lo que dejó el poder en manos de una junta militar. Durante ese mismo mes el congreso fue disuelto (Collier y Sater, 2004). La junta militar pronto se dividió debido a la intención de una parte de sus miembros de proponer un candidato del ala conservadora para la presidencia. Ante esta perspectiva dos ex miembros del comité naval-militar, Marmaduke Grove y Carlos Ibáñez, organizaron un nuevo golpe para deponer el gobierno de la junta el 23 de enero de 1925. El golpe fue exitoso y se impuso una nueva junta bajo el liderazgo del general Pedro Pablo Dartnell. El nuevo gobierno invitó a Alessandri a regresar al país con el fin de que reasumiera su posición en la presidencia del país. 
El 20 de marzo de 1925 Alessandri regresó a Chile a culminar su periodo presidencial que en ese momento era de cinco años. Aprovechando la coyuntura política en la que el congreso se encontraba disuelto el presidente se propuso llevar a cabo una reforma constitucional que pudiera abrir el camino hacia un régimen presidencialista, quitando poder al congreso. La reforma se aprobó por plebiscito del 3 de agosto con $93 \%$ del voto favorable (Collier y Sater, 2004, p. 213).

Fue durante este periodo de transición política que la misión Kemmerer llegó a Chile. Edwin Kemmerer era en ese momento profesor de economía en la Universidad de Princeton y ya había desempeñado funciones de asesor en cuestiones monetarias y financieras en distintos países. En 1924 fue el principal asesor económico de la Comisión Dawes encargada de renegociar los pagos de las deudas por reparaciones de Alemania. Una vez concluido el trabajo en Chile llevó su proyecto a otros países. De esta manera, entre 1923 y 1931 se encargó de la remodelación de los sistemas monetarios, fiscales y bancarios de Colombia, Ecuador, Bolivia, Perú, Sudáfrica, Polonia y China, además del caso chileno que se trata en este artículo. En todos los casos la reforma se basó en la creación de un banco central cuya principal función fuera defender el patrón oro, lo cual permitiría acceder al financiamiento internacional. Una vez que estalló la Gran Depresión estas políticas fueron abandonadas en la mayoría de los casos, debido a las presiones generadas por la crisis. Según Drake (1989), la intervención de Kemmerer en estos países ha sido vista tanto positiva como negativamente. En el primer caso se le considera como el pionero de leyes fiscales y financieras con bases científicas, así como el padre de ciertas instituciones como los bancos centrales. En el segundo se ve como quien abrió la puerta a la penetración y dominación estadunidense en la región. La interpretación correcta parece encontrarse en un punto intermedio entre ambas visiones.

Los primeros acercamientos para que Kemmerer visitara Chile como asesor en el establecimiento de un banco central y la instauración del patrón oro habían iniciado desde antes del gobierno de las dos juntas militares. A pesar de los cambios en el gobierno las negociaciones con Kemmerer no se detuvieron y una vez que Alessandri regresó a reasumir la presidencia se pudo concretar la visita. Con el fin de garantizar que las recomendaciones que hiciera el grupo de expertos no estuvieran sesgadas en favor del gobierno estadunidense, se optó por un contrato de carácter privado entre Kemmerer y el gobierno de Chile (Carrasco, 2009). La misión Kemmerer llegó a Chile el 2 de julio de 1925.

Existían tres motivos principales para invitar a Kemmerer a Chile. El primero de ellos era el control de la inflación y la estabilización de la moneda. "La inflación [... ] se percibía inusualmente elevada para esa época, cerca de $8 \%$ de aumento de los precios de consumo, según estudios posteriores, y el deterioro de las remuneraciones reales acrecentaba el descontento social" (Carrasco, 2009, p. 73). Los problemas con la inflación no eran nuevos para la economía chilena. Después de un intento fracasado de instaurar el patrón oro durante el periodo 1895-1898, los papeleros, aquellos que defendían el sistema monetario fundamentado en la emisión fiduciaria, tomaron el control del gobierno. La emisión de dinero por parte del gobierno y de los bancos se llevó a cabo sin restricciones ya que el valor de la moneda no estaba vinculado a ninguna mercancía, generando fuertes problemas inflacionarios (Drake, 1989; Kemmerer, 1926).

En segundo lugar, existía interés en el establecimiento de un banco central. Ya se habían realizado distintos intentos y se habían presentado proyectos para la fundación de la nueva institución, sin embargo, los debates parlamentarios y la falta de acuerdos habían frustrado cualquier intento para crear la nueva institución. Ante esto se pensó que lo mejor era traer a un experto extranjero que diera legitimidad al proyecto (Carrasco, 2009). 
Finalmente, la llegada de Kemmerer también permitiría “[...] facilitar los vínculos a un creciente dependencia de los Estados Unidos” (Drake, 1984, p. 32). Desde que terminó la primera guerra mundial las relaciones entre Chile y Estados Unidos se habían venido profundizando a costa del comercio con Gran Bretaña. Los flujos de capital provenientes de Estados Unidos también cobraron una importancia cada vez mayor, y para finales de la década de 1920 Chile era el principal destino de las inversiones estadunidenses en Sudamérica (Drake, 1984, p. 33).

Los tres objetivos estaban sumamente interrelacionados. Un vistazo a los antecedentes de Kemmerer deja claro que la manera en que se iba a lograr la estabilización de la moneda era mediante el establecimiento del patrón oro. Para el buen funcionamiento del sistema monetario era necesaria la existencia de un banco central encargado de regular las emisiones y supervisar el valor de la moneda. Además, el establecimiento del patrón oro otorgaría certidumbre a los inversionistas y comerciantes internacionales para llevar a cabo negocios con Chile. A ello hay que agregar la influencia que tenía Kemmerer en el contexto internacional, ya que, según Seidel (1972), su sola asesoría financiera era en muchos casos suficiente para mejorar las perspectivas del futuro económico de un país.

El patrón oro que se buscaba establecer en Chile consistía en el establecimiento de una paridad fija entre el oro y la moneda de cada país. Para ello se permitía el libre flujo de oro entre los países, así como la convertibilidad irrestricta entre oro y medios de pago. De esta manera los bancos comerciales y los bancos centrales tenían la obligación de entregar oro sin ninguna restricción ni descuento ante la presentación de cualquiera de los billetes bancarios o instrumentos de circulación que hubieran emitido. Ello iba en contra de las actividades en que habían incurrido los bancos y el gobierno en los años anteriores. Desde la primera guerra mundial los bancos habían emitido papel moneda teniendo como reserva bonos emitidos por el gobierno por los cuales recibían $8 \%$ de interés. $\mathrm{Al}$ mismo tiempo los bancos recibían depósitos del gobierno contra los cuales pagaban $6 \%$ de interés. Aunque en esta operación el gobierno pagaba más de lo que recibía, la emisión de billetes estaba de alguna forma respaldada por los bonos del gobierno (Kemmerer, 1926, p. 268). El patrón oro imponía un límite a este tipo de emisiones.

La paridad fija entre las monedas y el oro implicaba una paridad del mismo tipo entre las distintas monedas a nivel mundial. El patrón oro otorgaba certidumbre a las transacciones internacionales ya que el riesgo cambiario, aquél asociado a las pérdidas por fluctuaciones en el valor de las monedas, se reducía de manera considerable. Existía un compromiso por parte de las autoridades monetarias de cada país de defender la paridad con el oro (Eichengreen, 1996). Así, ante un déficit en la balanza de pagos que amenazara con una depreciación de la moneda, las autoridades monetarias del país en cuestión aplicarían políticas deflacionistas tales como disminuciones en la oferta monetaria y el gasto público y con ello contraer la demanda agregada, con el fin de reducir los precios en el interior, con exportaciones más competitivas e importaciones a la baja, al tiempo que la instauración de una tasa de interés más alta atraería capitales que permitirían defender el valor de la moneda y la paridad legal. En caso de una entrada excesiva de recursos debía aplicarse la política contraria. Esto es lo que se conoce como las reglas del juego del patrón oro.

Para 1925 el patrón estaba en un periodo de transición. Después de la primera guerra mundial la mayoría de los países participantes en el conflicto habían abandonado las paridades fijas. Durante los primeros años de la posguerra se dieron distintos debates respecto a la necesidad de regresar al patrón oro y la manera de hacerlo. En abril de 1925 Gran Bretaña, aún el centro financiero internacional, anunció el regreso al patrón oro con lo que se inauguró la era del patrón oro entreguerras (Kindleberger, 1984a). 
Como ya se mencionó, tres meses después llegó Kemmerer a Chile dispuesto a llevar a cabo las reformas necesarias para dar estabilidad al sistema monetario y financiero. La recepción para el grupo de expertos fue multitudinaria y calurosa, muestra que existía un respaldo generalizado desde gran parte de los sectores políticos y sociales (Carrasco, 2009; Drake, 1984, 1989). Eso no quiere decir que no hubiera detractores a la llegada de la misión. Según Drake $(1984$, p. 40) muchos banqueros, grandes terratenientes y ciudadanos ingleses residentes no mostraron tanto entusiasmo, aunque no se opusieron abiertamente. Si se lograba la instauración del patrón oro los banqueros deberían ajustar sus políticas de emisión, debido a la necesidad de respaldar los billetes con oro; mientras que según el mismo Kemmerer (1926) los terratenientes eran el único sector beneficiado por la inflación ya que podían pagar sus hipotecas con moneda depreciada: "Los grandes intereses de los terratenientes fueron por años, tanto en el Congreso como fuera de él, las fuerzas más poderosas a favor del papel moneda, el instrumento que les permitió cosechar lo que otros sembraron" (p. 269).

La mayoría de los sectores de la población se habían visto perjudicados por la inflación. El nivel de vida de los trabajadores disminuía ya que el aumento de salarios no alcanzaba a compensar el aumento en los precios, los ahorristas y tenedores de bonos debían aceptar pagos en moneda depreciada, y los capitalistas tenían que realizar sus inversiones en entornos de inestabilidad debido a las fluctuaciones del peso (Kemmerer, 1926). Los trabajos de la misión comenzaron inmediatamente y el 22 de agosto de 1925 se publicó en el Diario Oficial la reforma que creaba el Banco Central de Chile. La nueva ley bancaria se publicó el 26 de septiembre y la ley monetaria el 14 de octubre, unas semanas antes de la elección del congreso. La situación política se inclinó a favor de la aprobación de las leyes que pudieron ser decretadas sin mayores interrupciones. De hecho, las propuestas aprobadas no eran nuevas en el contexto chileno, pero el hecho de que vinieran del grupo de Kemmerer cambió su aceptación: "Los proyectos del Dr. Kemmerer no fueron distintos de las propuestas que ya habían hecho los economistas chilenos, pero que nunca fueron consideradas seriamente por el Congreso" (Llona, 1997, p. 155). La inexistencia del congreso permitió facilitar la instauración del nuevo sistema financiero-monetario chileno.

Como consecuencia de estas medidas se instauró el patrón oro en Chile. El oro se convirtió en la medida del valor y la acuñación se decretó libre y sin restricciones. La exportación e importación de oro también se liberalizó. El tipo de cambió se fijó en seis peniques de libra por peso. La reserva de oro de 300000000 de pesos del gobierno, la cual era suficiente para respaldar toda la emisión de billetes gubernamentales según el mismo Kemmerer, se depositó inmediatamente en el nuevo Banco Central ${ }^{1}$ el cual fue instruido para amortizar en oro todos los billetes en circulación. Asimismo, todos los billetes del gobierno fueron retirados y los billetes del Banco Central fueron los únicos autorizados legalmente para circular. La emisión debía respaldarse según la nueva ley por una reserva de oro del 50 \% que sería depositada una parte en Chile y la otra en Nueva York (Kemmerer, 1926). De esta manera Chile se unía a los demás países europeos que poco a poco iban reincorporándose al patrón oro después de años de inestabilidad en el valor de las monedas y como tal debía ser partícipe de las reglas del juego, es decir, que las políticas del Banco Central serían esencialmente pasivas y automáticas (Drake, 1984). Cuando ocurrieran entradas de oro al banco debidas a un superávit comercial, este debía disminuir las tasas de descuento con el fin de fomentar el crédito e indirectamente el consumo, para estimular de esta manera las importaciones

\footnotetext{
${ }^{1}$ Cada vez que la frase banco central aparece en minúsculas me refiero a la institución en términos generales, cuando aparece en mayúsculas, me refiero al Banco Central de Chile.
} 
restaurando el equilibrio con el exterior. En el caso que se presentara un déficit comercial, causando salidas de oro, las tasas de descuento debían aumentar encareciendo el crédito, disminuyendo el consumo, las importaciones y restaurando el equilibrio comercial. El Banco Central se convirtió en un instrumento de política monetaria reactivo cuyo objetivo principal era mantener la estabilidad en el valor de la moneda y defender la paridad peso-libra, restaurando los equilibrios en el comercio exterior. Ello se contraponía a una política monetaria activa cuyo objetivo era estimular la producción y el empleo.

\section{La PROSPERIDAD y La GRAN DePREsión}

Una vez que concluyó la reforma monetaria-financiera en Chile, las perspectivas para el sistema económico eran buenas. Kemmerer mismo veía con optimismo el futuro inmediato para el país. En un artículo de 1926 afirmó: "Con su moneda estabilizada, es razonable esperar que aumente la prosperidad en Chile y un comercio exterior creciente en el futuro inmediato. Hay buenas perspectivas de que los Estados Unidos sean un gran participante en este comercio creciente" (Kemmerer, 1926, p. 273). La sentencia probaría ser profética. No obstante, los efectos de esta vinculación con el exterior demostraron tener consecuencias negativas en el mediano plazo ante los efectos que la Gran Depresión tuvo sobre la economía chilena y el resto de América Latina.

El comercio exterior, de gran importancia en la economía chilena, se vio fuertemente estimulado en un primer momento por las reformas de Kemmerer y se volcó de lleno a los mercados internacionales. La proporción de la suma de las importaciones más las exportaciones respecto al PIB que había pasado de 43.7 en 1923 a 47.28 \% en 1925, dio un salto radical en 1926 cuando alcanzo 59.99 para después estabilizarse alrededor del $50 \%$ en los cuatro años posteriores (J. Braun et al., 2000, p. 163). Durante estos años se profundizó la dependencia de la economía chilena respecto a los vaivenes de la economía internacional . Los productos primarios siguieron siendo la fuente principal de recursos. La proporción de las exportaciones mineras como porcentaje del total siguió siendo muy alta. El cobre y el salitre continuaron siendo los principales productos de exportación para Chile, aunque el últilmo estaba perdiendo preeminencia en los mercados internacionales ante la aparición de sustitutos sintéticos (Palma, 1988).

Las exportaciones tuvieron un crecimiento de casi 38 \% para el periodo 1925-1929 (véase cuadro 11. En el caso de las importaciones, a pesar de que el comportamiento fue más inestable, la tasa de crecimiento para el mismo periodo fue de $32 \%$. Sin embargo, el monto de las importaciones se mantuvo por encima de las exportaciones durante este periodo, lo que significaba que había una salida neta de recursos debidos al comercio exterior. Con el patrón oro la presión a devaluar la moneda ante la escasez de divisas y el exceso relativo de moneda local, se hizo patente (véase gráfica 1).

La salida de recursos por concepto de comercio exterior fue más que compensada por la entrada de capitales y el endeudamiento externo. Como consecuencia de ello la balanza de pagos mantuvo un saldo positivo durante el periodo 1925-1929. Y a pesar de que el servicio de la deuda, el pago que debía hacerse cada año por concepto de intereses y amortización de la deuda ya existente, continuó representando un monto considerable, la adquisición de nuevos préstamos, sumando aquellos contraídos por el sector privado y el sector público, permitió que se mantuviera el flujo de recursos hacia la economía chilena. Mientras que en 1925 y 1927 la contratación de nuevos préstamos fue apenas menor al total del servicio de la deuda, en 1926 y 1928 el endeudamiento nuevo se disparó compensando con creces el déficit entre nueva deuda y servicio de deuda 
GUADRO 1. EXPORTACIONES MINERAS EN CHILE, 1925-1935

\begin{tabular}{lc}
\hline Año & Porcentaje del total \\
\hline 1925 & 83.9 \\
1926 & 86.1 \\
1927 & 86.8 \\
1928 & 85.5 \\
1929 & 88.4 \\
1930 & 83.7 \\
1931 & 84.9 \\
1932 & 69 \\
1933 & 74.4 \\
1934 & 75.8 \\
1935 & 79.4 \\
\hline
\end{tabular}

Fuente: J. Braun et al. (2000).

que se presentó en los dos años señalados. La deuda pública externa también creció durante estos años, pues entre 1925 y 1930 más que duplicó su valor. Como consecuencia de ello el stock de reservas internacionales brutas manejadas por el Banco Central mantuvo una tendencia creciente alcanzando un pico de 104300000 de dólares en 1928 (véase cuadro 2).

La economía chilena profundizó de esta manera su vínculo con el exterior. El crecimiento en las exportaciones mantuvo un ritmo menos acelerado que el de las importaciones, lo que obligó a recurrir aún más al financiamiento externo con tal de sostener el valor de la moneda y la paridad fija con la libra. El patrón oro permitió que el financiamiento siguiera llegando a pesar de que se mantenía el desequilibrio con el exterior, lo que impidió que se pudieran encontrar recursos para pagar los que estaban entrando. Chile entró en un proceso en el cual los nuevos préstamos podían utilizarse para pagar el servicio de la deuda existente, cubrir el déficit en la balanza comercial e incluso acumular reservas internacionales.

Uno de los principales objetivos de la misión Kemmerer, además de la vinculación de Chile con la economía internacional, fue la estabilización del valor de la moneda. Los resultados en este sentido fueron regulares. El balance fiscal del gobierno se logró consolidar mostrando únicamente un déficit importante en 1926. En el resto del periodo que va de 1925-1929 el balance fue positivo. Por su parte el problema de la inflación fue controlado de manera temporal. Después de que en 1926 se mostraron tasas negativas de crecimiento en los precios de $4.55 \%$, en 1927 y 1928 el nivel de inflación fue bastante bajo, no obstante, se volvió a disparar en 1929 (véase cuadro 3).

En lo que se refiere a la actividad económica, las tasas de crecimiento de la producción mostraron resultados contrastantes. La volatilidad en el crecimiento es patente si se compara la tasa de crecimiento de $22.5 \%$ en 1928 con la de 1926 que alcanzó una cifra negativa de $8.33 \%$. A pesar de la inestabilidad, considerando el periodo 1925-1929 la tasa de crecimiento para el PIB rondó $16 \%$, mientras que la del PIB per cápita alcanzó $10.09 \%$. El índice de la producción manufacturera mostró una tendencia de U para el periodo 1925-1929, alcanzando su mínimo en 1928 para después acercarse mucho al nivel de 1925. En este sentido podría hablarse de un estancamiento 
GRÁFICA 1. EXPORTACIONES E IMPORTACIONES (MILLONES DE PESOS DE 1995)

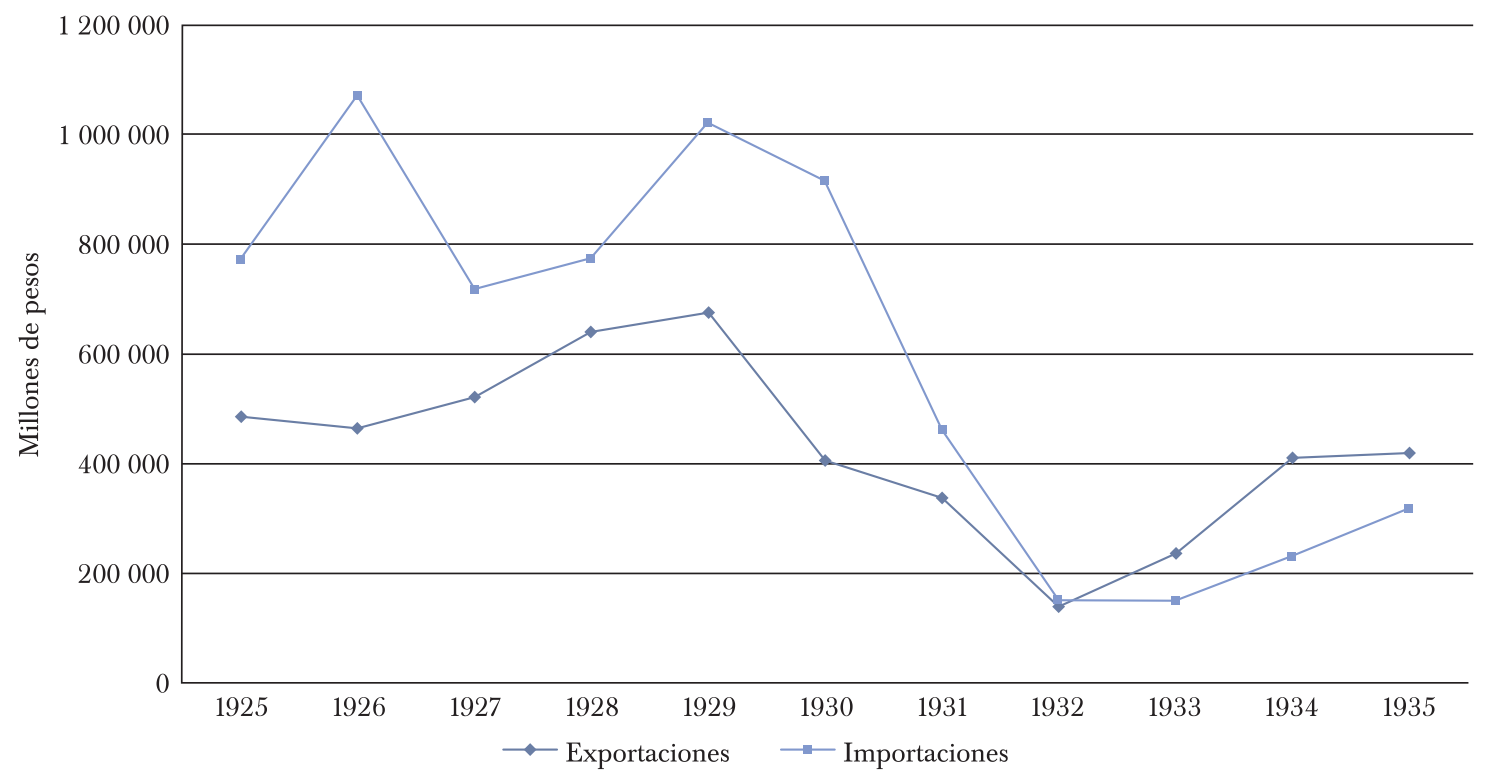

Fuente: J. Braun et al. (2000).

en la actividad manufacturera. Como era de esperarse, la producción que mostró más dinamismo fue la vinculada con el comercio exterior. La explotación de dos de los minerales de exportación más importantes creció de manera considerable durante estos cinco años (véase cuadro 4).

De ahí que en términos generales se puede afirmar que, para este periodo, como consecuencia de la estabilización y la vinculación de la economía chilena con el exterior los resultados fueron positivos en términos generales. Se alcanzaron niveles importantes de crecimiento, a pesar de la volatilidad en la tendencia de este. Las tasas de inflación disminuyeron de manera considerable, al tiempo que se logró consolidar el equilibrio fiscal. No obstante, existía un problema latente en la economía chilena. La expansión de estos años estuvo impulsada por el comercio exterior a costa del sector manufacturero y fue financiada por la entrada de recursos externos, los cuales pueden ser muy inestables en momentos de crisis.

En octubre 1929 ocurrió el crack de la bolsa de valores de Nueva York. Este acontecimiento marcó el inicio de lo que se conoció como la Gran Depresión, un periodo de estancamiento económico que duró aproximadamente diez años y que se generalizó a gran parte de la economía internacional. El efecto de la Gran Depresión sobre Chile ocurrió a través de los mercados internacionales. Ante los problemas que enfrentaba cada país comenzaron a generalizarse las medidas proteccionistas. Ello hizo que las exportaciones chilenas cayeran de manera abrupta. En 1932 las exportaciones disminuyeron 79 \% respecto a su valor máximo en 1929. Sin embargo, el descenso en las importaciones fue más pronunciado. El punto mínimo en este caso se alcanzó en 1933 cuando las importaciones representaron sólo $14.62 \%$ de lo que fueron en 1929. Ante la caída en el monto de exportaciones, el caudal disponible para adquirir recursos en el exterior disminuyó, lo que impidió continuar con el ritmo de crecimiento que llevaban las importaciones. Como consecuencia, la proporción del comercio exterior en el PIB alcanzó un mínimo de 19 \% en 1933, 
CUADRO 2. SITUACIÓN EXTERNA EN CHILE, 1925-1935

\begin{tabular}{|c|c|c|c|c|c|c|}
\hline Año & $\begin{array}{l}\text { Total nuevos } \\
\text { préstamos }\end{array}$ & $\begin{array}{l}\text { Total servicio } \\
\text { deuda }\end{array}$ & $\begin{array}{l}\text { Cuenta } \\
\text { corriente }\end{array}$ & $\begin{array}{l}\text { Balanza } \\
\text { de pagos }\end{array}$ & $\begin{array}{c}\text { Stock de reservas } \\
\text { internacionales brutas }\end{array}$ & $\begin{array}{l}\text { Deuda pública } \\
\text { externa }\end{array}$ \\
\hline & \multicolumn{5}{|c|}{ Millones de dólares } & Millones de \\
\hline 1925 & 22.58 & 25.88 & 65.85 & 75.22 & - & 427080 \\
\hline 1926 & 86.29 & 31.15 & 30.28 & 99.16 & 96.2 & 651061 \\
\hline 1927 & 27.57 & 30.24 & 56.24 & 72.36 & 93.4 & 678463 \\
\hline 1928 & 94.72 & 55.71 & 70.28 & 129.05 & 104.3 & 798821 \\
\hline 1929 & 44.58 & 36.86 & 59.36 & 89.97 & 92.4 & 825933 \\
\hline 1930 & 61.5 & 37.1 & -34.18 & 15.93 & 70.4 & 1008339 \\
\hline 1931 & - & 27.19 & -7.29 & -17.24 & 39.4 & 1189584 \\
\hline 1932 & - & - & - & - & 33.8 & 3638378 \\
\hline 1933 & - & - & - & - & 35.2 & 3277068 \\
\hline 1934 & - & - & - & - & 33.4 & 2286462 \\
\hline 1935 & - & - & - & - & 31.2 & 2224225 \\
\hline
\end{tabular}

Fuente: J. Braun et al. (2000).

CUADRO 3. BALANCE FISGAL E INFLACIÓN EN CHILE, 1925-1935

\begin{tabular}{|c|c|c|c|c|}
\hline Años & $\begin{array}{r}\text { Ingresos fiscales } \\
\text { Millor }\end{array}$ & $\begin{array}{l}\text { Gastos fiscales } \\
\text { es de pesos de }\end{array}$ & $\begin{array}{l}\text { Balance fiscal } \\
1995\end{array}$ & $\begin{array}{c}\text { Variación índice } \\
\text { de precios al consumo } \\
\text { Porcentaje }\end{array}$ \\
\hline 1925 & 333214 & 271264 & 61950 & 7.71 \\
\hline 1926 & 251581 & 326903 & -75322 & -4.55 \\
\hline 1927 & 298017 & 301867 & -3850 & 1.22 \\
\hline 1928 & 444337 & 329417 & 114920 & 0.45 \\
\hline 1929 & 379941 & 324243 & 55698 & 7.4 \\
\hline 1930 & 380183 & 434746 & -54563 & -5.18 \\
\hline 1931 & 269465 & 322646 & -53181 & 0 \\
\hline 1932 & 153639 & 158992 & -5353 & 23.64 \\
\hline 1933 & 274649 & 239012 & 35637 & 4.42 \\
\hline 1934 & 315157 & 255952 & 59205 & 4.23 \\
\hline 1935 & 446337 & 336557 & 109780 & -1.36 \\
\hline
\end{tabular}

Fuente: J. Braun et al. (2000). 
GUADRO 4. INDICADORES DE PRODUCGIÓN EN CHILE, 1925-1935

\begin{tabular}{cccccc}
\hline & $\begin{array}{c}\text { Tasa de crecimiento } \\
\text { Años }\end{array}$ & $\begin{array}{c}\text { Tasa de crecimiento } \\
\text { del PIB real } \\
\text { per cápita }\end{array}$ & $\begin{array}{c}\text { Producción } \\
\text { de cobre }\end{array}$ & $\begin{array}{c}\text { Producción } \\
\text { de salitre }\end{array}$ & $\begin{array}{c}\text { Indice de producción } \\
\text { manufacturera }\end{array}$ \\
\hline \multicolumn{5}{c}{ Porcentaje } & \multicolumn{3}{c}{ Toneladas } & $1960=100$ \\
1925 & - & - & 193000 & 2525536 & 30.18 \\
1926 & -8.33 & -9.53 & 203000 & 2016698 & 27.61 \\
1927 & -1.81 & -3.1 & 243000 & 1614082 & 26.61 \\
1928 & 22.5 & 20.91 & 287000 & 3164824 & 27.79 \\
1929 & 5.23 & 3.86 & 321000 & 3233321 & 29.99 \\
1930 & -16.01 & -17.24 & 220000 & 2445834 & 28.42 \\
1931 & -21.22 & -22.36 & 224000 & 1126000 & 23.02 \\
1932 & -15.5 & -16.74 & 103000 & 694000 & 23.23 \\
1933 & 23.22 & 21.42 & 163000 & 438000 & 26.12 \\
1934 & 20.72 & 18.98 & 257000 & 812000 & 29.52 \\
1935 & 5.75 & 4.2 & 267000 & 1218000 & 33.25 \\
\hline
\end{tabular}

Fuente: J. Braun et al. (2000).

únicamente una tercera parte de lo que llegó a representar en 1929. "El valor oro del comercio internacional cayó proporcionalmente más que el de ningún otro país en el mundo” (Drake, 1984, p. 52).

El efecto inmediato en el comercio internacional fue la merma en los ingresos fiscales; para el periodo 1930-1932 -en términos de pesos de 1995- fue de $59.59 \%$. Debido a la necesidad de mantener el equilibrio fiscal, una máxima que en ese momento no era cuestionada, los gastos fiscales tuvieron un comportamiento similar. En pesos reales dicho descenso superó la de los ingresos ya que la tasa de crecimiento fue de $-63.43 \%$. Sin embargo, el esfuerzo no fue suficiente y el balance fiscal fue deficitario durante los tres años mencionados. El recorte del gasto no fue suficiente para cubrir el recorte de los ingresos. Por tanto, el déficit no representó una política fiscal expansiva, sino más bien la incapacidad del gobierno chileno para ajustar sus finanzas.

Los problemas en el comercio exterior también se manifestaron en las tasas de crecimiento de la economía en su conjunto. Para 1930 el PIB real tuvo un impresionante descenso de 16.01 puntos porcentuales, el cual fue seguido por uno aún más profundo en 1931 de $21.22 \%$. En 1932 los problemas continuaron ya que la tasa de crecimiento fue de -15.50 por ciento.

\section{El ABANDONO DEL PATRÓN ORO Y LA POLÍTICA ECONÓMICA, 1929-1932}

Para el momento en que estalla la crisis en 1929 el gobierno chileno contaba con recursos limitados de política económica para enfrentarla. La pertenencia al patrón oro limitaba las posibilidades de la política monetaria como un instrumento expansivo. Como ya se mencionó, Kemmerer había indicado que el Banco Central debía aplicar una política pasiva y reactiva. Las únicas variables que debían interesar a esta institución eran el saldo de la balanza de pagos, las reservas internacionales 
y la paridad peso-libra. Ni los niveles de actividad económica ni los de empleo debían ser una preocupación para la institución. La tasa de interés sólo debía ser utilizada para responder a salidas o entradas de recursos que amenazaran la estabilidad del valor de la moneda.

Por otro lado, el tipo de cambio era un objetivo y no un instrumento. Las políticas devaluatorias para estimular las exportaciones estaban descartadas por completo. Después de todo, la credibilidad de la economía chilena en el contexto del patrón dependía de defender la paridad fija establecida en 1925. El Banco Central tenía como misión fundamental defender esa paridad. Se pensaba que en momentos de crisis el compromiso con el patrón oro permitiría la entrada de flujos de capitales que resolverían los problemas.

En 1931 esta visión de la política monetaria fue reafirmada por el mismo Kemmerer quien fue consultado respecto al mejor rumbo a seguir. La respuesta del asesor fue la esperada ya que "[...] recomendó la elevación de las tasas de descuento, la contracción severa de la oferta monetaria, el mantenimiento absoluto de la convertibilidad y el depósito de prácticamente toda la reserva de oro en Nueva York" (Drake, 1989, p. 121). Los chilenos estaban probando ser buenos aprendices ya que incluso antes de consultar a Kemmerer la política recomendada ya se estaba llevando a cabo. Lo más importante para las autoridades monetarias era detener la salida neta de recursos. En agosto de 1930 se dio el primer aumento de la tasa de redescuento que pasó de 6 a $7 \%$, y en mayo de 1931 se aumentó primero a 8 y unos pocos días después a 9 \% (Banco Central de Chile, 1932). Como consecuencia, la tasa de interés nominal aumentó. El crédito se hizo más caro y la emisión de dinero disminuyó en forma paralela.

Los agregados monetarios cayeron de manera considerable desencadenando un proceso deflacionario. El aumento de precios, que había sido históricamente el problema de la economía chilena, ahora abría paso hacía una caída en el nivel general de precios al consumidor. En 1930 el nivel de precios disminuyó 5.18 \% y en 1931 se mantuvo estable. Si la inflación genera problemas en el interior de los sistemas económicos la deflación tiene efectos devastadores. Los precios bajos hacen que las expectativas de ganancia de los empresarios disminuyan lo que detiene la inversión y la actividad económica. El empleo, los salarios y la producción caen como consecuencia de todo ello. Además, el pago de las deudas se complica ya que el dinero vale más en el momento en que se realiza el pago que en el momento en que se contrataron, afectando principalmente a los deudores, que generalmente son los mismos empresarios o incluso el gobierno, beneficiando a los acreedores, es decir, a los bancos (véase cuadro 5)

Pese a ello, la deflación era el efecto que se esperaba con la política monetaria seguida por el Banco Central. Los precios bajos debían estimular las exportaciones y mermar las importaciones al tiempo que el aumento en las tasas de interés debía atraer capitales. Una vez que ello ocurriera los problemas de balanza de pagos se resolverían y la economía volvería al equilibrio. No obstante, los mercados externos estaban paralizados. Los capitales ya no estaban fluyendo y había caído la demanda internacional de productos.

Las reservas internacionales siguieron cayendo a pesar de los esfuerzos del Banco Central. En el transcurso de tres años $60 \%$ de las reservas se había esfumado, ya que en 1931 únicamente alcanzaban los 39400000 de dólares (véase cuadro 2). Chile pasó de ser un importador neto a un exportador neto de recursos. El financiamiento había dejado de llegar, sin embargo, y el país tenía que seguir pagando la deuda externa. La merma en los ingresos fiscales sólo profundizó los problemas. 
CUADRO 5. INDICADORES MONETARIOS EN CHILE, 1925-1935

\begin{tabular}{cccccccc}
\hline \multicolumn{7}{c}{ M1 } & \multicolumn{2}{c}{$\begin{array}{c}\text { Emisión } \\
\text { del Banco } \\
\text { Central }\end{array}$} & $\begin{array}{c}\text { Tasa interés } \\
\text { nominal efectiva } \\
\text { cobrada a } \\
\text { corto plazo }\end{array}$ & $\begin{array}{c}\text { Tasa interés real } \\
\text { efectiva cobrada } \\
\text { a corto plazo }\end{array}$ & $\begin{array}{c}\text { Pesos chilenos } \\
\text { por libra }\end{array}$ & $\begin{array}{c}\text { Pesos chilenos } \\
\text { por dólar }\end{array}$ \\
\hline \multicolumn{7}{c}{ Tasas de crecimiento } & \multicolumn{2}{c}{ Promedio anual } & \multicolumn{2}{c}{ Promedio anual } \\
1925 & - & - & - & 9.0 & 1.2 & 40.99 & 8.55 \\
1926 & -0.48 & -6.64 & 7.17 & 9.0 & 14.19 & 39.58 & 8.15 \\
1927 & -14.99 & -3.98 & -5.79 & 9.0 & 7.69 & 39.31 & 8.27 \\
1928 & 13.98 & 19.32 & 13.68 & 9.3 & 8.82 & 39.55 & 8.22 \\
1929 & -4.46 & -3.03 & -3.02 & 9.2 & 1.65 & 39.56 & 8.25 \\
1930 & -17.06 & -14.74 & -13.11 & 9.4 & 15.32 & 39.87 & 8.26 \\
1931 & -6.08 & -16.69 & 4.61 & 9.5 & 9.5 & 42.86 & 9.45 \\
1932 & 69.33 & 38.64 & 66.69 & 9.5 & -11.43 & 126.57 & 36.1 \\
1933 & 17.89 & 14.94 & 1.99 & 8.3 & 3.69 & 132 & 34.02 \\
1934 & 17.18 & 13.88 & -1.83 & 7.3 & 2.97 & 125.84 & 24.74 \\
1935 & 8.19 & 11.25 & 5.42 & 7.2 & 8.65 & 123.59 & 25.07 \\
\hline
\end{tabular}

Fuente: J. Braun et al. (2000).

Aunado a los obstáculos económicos se suscitaron conflictos políticos. El gobierno chileno se declaró insolvente para seguir con el apoyo a las obras públicas y para pagar los salarios de los empleados públicos. El desempleo comenzó a crecer lo que causó protestas generalizadas por parte de los trabajadores. La presión creció tanto que Carlos Ibáñez del Campo, que había llevado un gobierno populista autoritario, se vio obligado a renunciar en julio de 1931. El cargo fue ocupado por Juan Esteban Montero durante los siguientes meses. (Vergara, 2015)

De acuerdo con Marfan (1984), en agosto de 1931 el pago de la deuda se volvió insostenible por lo que Chile entró en cesación de pagos, unos días después de que se instituyó el control de cambios: "Estas dos medidas permitieron relajar las presiones financieras de la balanza de pagos y ejercer un control directo sobre las importaciones" (p. 99). En 1932 el déficit comercial continuó; sin embargo, su magnitud fue mucho menor que en años anteriores y para 1933 el comercio mostró un balance favorable.

Ante el nuevo entorno el Banco Central reaccionó de la manera que correspondía. Junto con la cesación de pagos, la tasa de redescuento pudo ser nuevamente revisada en agosto de 1931, pero esta vez a la baja, hasta un nivel de $8 \%$. En las siguientes semanas se hicieron revisiones a la baja hasta que el 26 de octubre de 1931 el nivel se estableció en $6 \%$ (Banco Central de Chile, 1932). A pesar de ello la tasa de interés cobrada por el sector bancario se mantuvo alrededor de $9.5 \%$, y en términos totales la emisión y los agregados monetarios siguieron cayendo aun en este año.

Pero se estaban dando los primeros pasos en la búsqueda de una política que permitiera resolver la problemática. La cesación de pagos otorgó más margen de maniobra al gobierno chileno y limitó la salida de recursos. Por su parte, el control de pagos generó una pequeña devaluación en la paridad peso-libra. El patrón oro seguía vigente por lo que esta pequeña devaluación aún caía dentro de lo esperado bajo las reglas del juego en un contexto internacional como el que se presentaba en 1931 . 
La situación internacional dio un vuelco en septiembre de 1931 cuando Gran Bretaña abandonó el patrón oro (Kindleberger, 1984a). Aunque Estados Unidos había pasado a ocupar una función cada vez más importante en el contexto financiero internacional, Gran Bretaña aún mantenía una posición importante. Según Rosemary Thorp (1984), una vez que se instituyó el patrón oro hubo demasiados centros. Estados Unidos no tenía la experiencia para ocupar la posición, y en Francia no se tuvo la disposición. Aunque Gran Bretaña se encontraba en declive no había sido desplazado por completo. Una vez que el defensor histórico del patrón oro abandonó la paridad fija la puerta se abrió para el resto de los países. Como consecuencia de esta medida se perdió una parte de las reservas en oro del Banco Central de Chile depositadas en Gran Bretaña. Las instituciones poseedoras de las reservas ya no tenían la obligación de entregar los depósitos en oro (Kindleberger, 1984a).

Chile abandonó finalmente el patrón oro en marzo de 1932, ante la imposibilidad de seguir manteniendo la paridad debido a la gran salida de recursos. Esta medida tuvo que tomarse a pesar de que, según Drake (1984), en el gobierno algunos "líderes económicos" aún creían que las ideas de Kemmerer debían ser la regla y esperaban que el abandono fuera algo temporal para superar las dificultades. A ellos se contraponían algunas elites chilenas que desde los comienzos de la depresión exigían el abandono del patrón oro y la búsqueda de políticas alternativas que pusieran en marcha la recuperación. Al final, la falta de recursos obligó a tomar una medida que en buena parte de la cúpula gubernamental no era bien vista.

La consecuencia inmediata fue la devaluación de la moneda. A pesar de que la libra se había devaluado también en 1931, como consecuencia del abandono del patrón oro, la paridad pesoslibra se triplicó de 1931 a 1932 pasando de 42.86 pesos por libra en promedio a 126.57. El Banco Central ya no tenía la misión de mantener una paridad fija y modificó su política monetaria, sin embargo, el entorno de crisis continuaba.

Las emisiones de dinero crecieron de manera exponencial en 1932 alcanzando una tasa de $66.69 \%$ mientras que al agregado monetario M1 ${ }^{2}$ alcanzó un crecimiento de $69.33 \%$. Sin embargo, nada de ello se hizo como consecuencia de una política explícita de reactivación económica (Marfan, 1984). Una vez que las restricciones del patrón oro fueron abandonadas, el Banco Central comenzó a utilizarse para financiar el déficit del gobierno. El objetivo primordial era llenar el boquete en las finanzas públicas (Toso y Feller, 1983). En 1932 el Banco Central financió al gobierno hasta por 492000000 de pesos, en comparación con los 34000000 de pesos que representaban el total de la deuda del gobierno con esta institución en julio de 1931 (Marfan, 1984). Al 31 de diciembre de 1932, 84.6\% de las inversiones colocadas por el Banco Central fueron créditos al gobierno, y sólo 11.9 \% créditos concedidos a otras instituciones. Únicamente el $3.5 \%$ restante fueron operaciones de descuento y redescuento, actividades que en teoría serían las principales de un banco central (Banco Central de Chile, 1933).

Las nuevas emisiones se vieron acompañadas por nuevas reducciones en la tasa de redescuento. El 19 de febrero de 1932 la tasa quedó en un nivel de $5.5 \%$ y el 23 de agosto se redujo aún más hasta alcanzar 4.5 puntos porcentuales (Banco Central de Chile, 1933). No obstante, la tasa de in-

\footnotetext{
${ }^{2}$ Los agregados monetarios miden la oferta monetaria, es decir, la cantidad de dinero en circulación, y se dividen de acuerdo con su liquidez, su capacidad de transformarse en billetes y monedas. De esta manera M1 incluye básicamente billetes y monedas en circulación, así como depósitos bancarios que pueden transformarse fácilmente en billetes y monedas, o que pueden utilizarse ellos mismos como medios de pago. M2 incluye M1 más cierto tipo de activos financieros menos líquidos que los depósitos bancarios; que no pueden transformarse en billetes y monedas con la misma facilidad. M3 incluye M2 más activos financieros que son aún menos líquidos, y así sucesivamente.
} 
terés nominal se mantuvo en el mismo nivel. Esto hace pensar en la existencia de una trampa de liquide $3^{3}$ para este momento en la economía chilena, ya que, existían fuertes expectativas negativas (Riveros, 2009, p. 16). Los resultados económicos del año anterior junto con el estancamiento en el nivel de precios no auguraban una salida rápida de la depresión.

A pesar de que la emisión de dinero no fue consecuencia de una política monetaria expansiva, el efecto sobre el nivel de precios permitió superar las tendencias deflacionarias. El nivel de precios creció $23.64 \%$ en 1932. El abandono del patrón oro había permitido que el Banco Central modificara sus objetivos y, a pesar de haberse convertido en un instrumento de financiamiento del gobierno, la no supeditación al objetivo del tipo de cambio permitió que la política monetaria impulsara al alza el nivel de precios. La inflación permitió aliviar el peso de las deudas y amplió el crédito. Drake comparte esta opinión al afirmar: "Esta expansión monetaria ayudó a Chile a iniciar la recuperación de la depresión, la cual comenzó en pleno en 1933” (Drake, 1989, p. 121).

\section{LA RECUPERACIÓN Y LAS POLÍTICAS ANTICÍCLICAS, 1933-1935}

A finales de 1932 Arturo Alessandri volvió a asumir el puesto de presidente que había ocupado ya durante el periodo 1920-1925. Montero renunció al cargo en junio de 1932 debido a un golpe militar que marcó el inicio de la república socialista que se mantuvo durante cien días, a la cual le sucedió una junta militar que finalmente llamó a elecciones en octubre, tras las cuales Alessandri fue electo. El nuevo presidente asumió el cargo respaldado por una coalición política de centroderecha e implantó medidas estrictas de estabilización económica (Vergara, 2015).

El contexto económico que enfrentó la nueva administración era complicado. En 1932 la inflación había vuelto a hacer su aparición, pero acompañada por tasas de crecimiento negativas del producto. Además, las exportaciones y las importaciones habían alcanzado su nivel más bajo durante todo el periodo de crisis, aunque se había logrado reducir el déficit comercial.

A favor del nuevo gobierno se encontraba el cese de pagos de la deuda y la instauración del control de cambios que permitía mayor control sobre las importaciones, todo lo cual evitaba la sangría de recursos. Además, el patrón oro ya había sido abandonado y retornar a este régimen no era viable ante los bajos niveles de las reservas de oro, y altos niveles de emisión provocados por el financiamiento del déficit público. Defender la paridad en este contexto hubiera sido prácticamente imposible. Los instrumentos monetarios estaban a disposición del gobierno en caso de utilizar la política monetaria para impulsar el crecimiento.

La nueva administración aprovechó estas perspectivas y logró consolidar la recuperación de la economía chilena. Los problemas con la producción y el desempleo habían llevado ya a fuertes episodios de inestabilidad política. La recuperación económica era necesaria si la nueva administración quería mantenerse. La producción volvió a la senda del crecimiento alcanzando tasas de 23.22, 20.72 y $5.75 \%$ para el periodo 1933-1935. Las exportaciones se beneficiaron del contexto internacional, lo que permitió mantener un superávit comercial durante los tres años menciona-

\footnotetext{
${ }^{3}$ La trampa de liquidez es un concepto acuñado por Keynes en la Teoría general sobre la ocupación, el interés y el dinero, en 1936. Ocurre cuando la demanda de dinero es absoluta debido a las expectativas negativas en la economía. Las personas prefieren guardar el dinero que gastarlo inmediatamente, ya que creen que en el futuro la situación empeorará. Por lo tanto, cualquier intento del banco central por disminuir la tasa de interés de mercado es inútil, ya que los nuevos recursos no entran al mercado, la oferta de crédito no aumenta, y por tanto no se logra la caída en la tasa de interés. Ello significa que la política monetaria se vuelve estéril en estos contextos para estimular la demanda agregada y la producción.
} 
dos. El nivel de precios creció, pero a tasas manejables, siendo el máximo de $4.42 \%$ en 1933 , y en 1935 incluso se presentó deflación con una tasa negativa de crecimiento de los precios de $1.36 \%$. El tipo de cambio también pudo estabilizarse después de la fuerte devaluación causada por el abandono del patrón oro.

Las causas de la recuperación son difíciles de identificar. Las exportaciones mostraron un alto dinamismo durante el periodo 1933-1935. Tomando como punto de referencia 1932, el valor de las exportaciones se multiplicó por tres para 1935, aunque continuaban siendo $37.62 \%$ menores que las de 1929. Las importaciones pudieron contenerse gracias al control de cambios y los aranceles.

Pero no fue sólo el comercio internacional el que ayudó a sacar a Chile de la depresión. La producción interna se vio beneficiada de las políticas económicas que comenzó a aplicar el gobierno. La política monetaria y fiscal, la devaluación del peso, los aranceles y los controles de cambio permitieron que la demanda se orientara de una manera muy importante hacia el mercado interno (Palma, 1988, p. 90). El mercado nacional fue capaz de cubrir las necesidades de la demanda evitando que los ingresos obtenidos por el crecimiento de las exportaciones salieran mediante la compra de productos extranjeros, como había ocurrido en los años anteriores a la crisis. La participación de la agricultura y de las manufacturas en el PIB creció en comparación con 1929 a costa de la minería. La oferta de la producción nacional dentro de la oferta total de manufacturas en Chile llegó a alcanzar el 90 \% en comparación con la proporción de 60 \% que representó en 1928-1929 (Palma, 1988, p. 93). La estructura productiva pudo cubrir el mercado en parte por el crecimiento que estaba mostrando, y en parte por los bajos niveles de actividad económica que se mantenían en comparación al periodo anterior a la crisis (véase cuadro6).

La práctica de la política fiscal dentro de este proceso fue marginal. El gasto del gobierno creció a altas tasas durante estos tres años, sin embargo, los ingresos crecieron en una proporción mayor. Ello permitió mantener superávit fiscales constantes durante el periodo. Los ingresos crecieron gracias a la reactivación de la actividad económica y del comercio exterior, pero también se modificó la estructura tributaria. Todas las tasas de impuestos fueron elevadas y se instauró un impuesto indirecto en la compra-venta de bienes (Marfan, 1984). Ello permitió que en 1935 se alcanzarán ingresos fiscales que superaban lo que se había logrado recaudar durante el periodo precrisis.

El crecimiento del gasto también fue acelerado, pero no en la misma magnitud que los ingresos. El superávit fiscal de 1935 fue el más alto del periodo analizado en este trabajo, con excepción del de 1928. El crecimiento del gasto sirvió únicamente para alcanzar los niveles anteriores al estallido de la crisis. Los gastos fiscales alcanzaron un máximo en 1930, en el cual el déficit también alcanzó su nivel máximo, justo en medio de la fase más profunda de la depresión, en el segundo peor año del periodo medido en términos de PIB real (véase cuadro 3). En 1932 los gastos fiscales habían caído 63.42 \% respecto a 1930, y fue a partir de ese punto que empezó el fuerte crecimiento del gasto del gobierno, aunque no se recuperó por completo. Se trató de una recuperación del gasto gubernamental siguiendo la tendencia de los ingresos y del desempeño económico.

El gasto creció a un ritmo mucho menor que los ingresos. Mientras que los ingresos prácticamente se triplicaron entre 1932 y 1935, los gastos se duplicaron. El gobierno chileno estaba extrayendo más recursos del sistema económico, de los que estaba inyectando, estaba reduciendo la demanda agregada. En los momentos más profundos de la crisis se aplicaron reformas fiscales que tuvieron el único objetivo de aumentar la recaudación, lo que va en contra de cualquier política expansiva, en la cual el gasto deficitario es un instrumento fundamental para impulsar la producción. 


\section{CUADRO 6. PARTICIPACIÓN DE SECTORES DE ACTIVIDAD ECONÓMICA EN EL PIB EN CHILE, 1925-1935}

\begin{tabular}{ccccc}
\hline Año & Agricultura & Mineria & $\begin{array}{c}\text { Manufacturas } \\
\text { Porcentaje del PIB }\end{array}$ & $\begin{array}{c}\text { Servicios } \\
\text { gubernativos }\end{array}$ \\
\hline \multicolumn{5}{c}{. } \\
\hline 1925 & 9.85 & 25.72 & 11.39 & 4.32 \\
1926 & 11.2 & 24.94 & 11.37 & 3.86 \\
1927 & 12.2 & 24.39 & 11.16 & 3.66 \\
1928 & 12.46 & 30.02 & 9.51 & 2.41 \\
1929 & 11.33 & 30.41 & 9.75 & 2.74 \\
1930 & 12.51 & 26.38 & 11.01 & 2.75 \\
1931 & 14.55 & 22.32 & 11.32 & 3 \\
1932 & 16.82 & 15.38 & 13.51 & 2.85 \\
1933 & 17.49 & 14.7 & 12.33 & 3.66 \\
1934 & 15.93 & 19.02 & 11.55 & 3.39 \\
1935 & 12.51 & 20.96 & 12.3 & 4.03 \\
\hline
\end{tabular}

Fuente: J. Braun et al. (2000).

Había interés en estimular la actividad económica, pero el gasto público no era visto como el mecanismo para resolver el desempleo. En este sentido Ernesto Barros, quien había sido ministro del Interior por un breve periodo en 1932, afirmaría: "Se descubrió (como se ha hecho en todas partes) que un programa de obras públicas es inevitablemente la forma más costosa y menos eficiente de apoyar el empleo, mientras que, por otra parte, el seguro de desempleo tiende a quebrantar la moral y la dignidad de los desempleados" (Barros, 1935, p. 640). El objetivo era lograr que fuera el sector privado el que resolviera los problemas de producción y empleo. El gobierno se limitó a estimular la inversión privada en lugar de participar directamente en el proceso de producción (Barros, 1935). De ahí que no se pueda hablar de una política fiscal expansiva, al contrario de lo que afirman Palma (1988) y Marfan (1984).

La forma que encontró el gobierno chileno para estimular la actividad privada fue el crédito. Para que la estrategia fuera exitosa la política monetaria debía tener una participación determinante. Según Marfan (1984), la política monetaria siguió una lógica contractiva en estos años, partiendo del hecho de que el financiamiento otorgado por el Banco Central al gobierno disminuyó una vez que se hubo estabilizado el balance fiscal. Aunque ello es cierto, la emisión y los agregados monetarios continuaron creciendo, aunque a ritmos menores que en 1932. Ello garantizó que el crecimiento se mantuviera sin generar las presiones inflacionarias causadas por el rápido incremento en la circulación monetaria ocurrido una vez que se hubo abandonado el patrón oro.

La expansión de los agregados monetarios, a pesar del descenso en el financiamiento al gobierno por parte de Banco Central y en la emisión de dinero en 1934, se puede explicar por las facilidades de crédito que proveía la institución. Los cambios en la política crediticia son explicados por Guillermo Subercaseaux, entonces presidente del Banco Central de Chile "Desde 1932 se habían dictado diversas leyes que obligaban al Banco Central a financiar instituciones de fomento, o sea, a proporcionarles créditos para el efecto que estas hicieran préstamos a bajo interés a la 
agricultura, a la industria, a la minería, etc." (Subercaseaux, 1938, p. 7). Ello permitió financiar la expansión de la actividad económica. El Banco Central pudo ser utilizado como un instrumento de política monetaria, gracias al abandono de las restricciones impuestas por el patrón oro, a pesar incluso de que el mismo Subercaseaux no estaba del todo conforme con el nuevo papel que había jugado el banco: "todas estas disposiciones legales que vinieron a obligar al Banco Central a proporcionar créditos que no eran de carácter bancario ni propios para una institución reguladora del medio circulante, significaban un obstáculo grave para su correcto funcionamiento." (Subercaseaux, 1938, p. 8).

\section{Conclusiones}

La política monetaria y fiscal en Chile durante el periodo de 1925 a 1935 estuvo caracterizada por un apego muy marcado a las políticas tradicionales. El patrón oro fue en gran medida responsable de ello, sin embargo, incluso después de que se hubo abandonado la paridad fija las reacciones de la política gubernamental ante los efectos de la crisis no se modificaron de manera radical.

La utilización del gasto público con fines expansivos estaba fuera de discusión. En los momentos más profundos de la crisis el primer objetivo del gobierno fue mantener el equilibrio fiscal. Cuando se recurrió a la ampliación de las emisiones del Banco Central, fue únicamente con la intención de financiar el déficit público, sin la intención de estimular la actividad económica mediante la expansión de las operaciones de banca central.

Las condiciones obligaron a tomar medidas alternativas para salir de la crisis. No fue hasta que la presión sobre el gobierno fue insostenible, incluso provocando la renuncia del presidente, que la política económica dio un giro. La decisión de imponer el control de cambios, cesar los pagos de la deuda externa y abandonar el patrón oro fue tomada debido a las circunstancias. Simplemente ya no fue posible mantener el sistema monetario implementado por Kemmerer ante la caída en las reservas y las presiones para el pago de las deudas.

Una vez que el patrón oro cayó se abrió la puerta hacia la recuperación. La política dejó de estar supeditada a los objetivos externos y comenzó a preocuparse por el mercado interno. No había nada que hacer en lo que se refería al comercio exterior y los flujos de capitales. Sin importar qué política siguiera Chile la salvación no llegaría desde el exterior a menos que las condiciones internacionales cambiaran. Fue entonces cuando la administración de Alessandri decidió modificar el curso de la política que se había seguido hasta entonces, aunque a regañadientes.

El principal cambio vino en la política monetaria. Las tasas de descuento se redujeron y el Banco Central fue utilizado para expandir el financiamiento. A ello se agregó la recuperación en los mercados internacionales. De esta forma Chile logró superar la crisis gracias a una mezcla de expansión interna financiada por los créditos del Banco Central y expansión externa estimulada por la recuperación el comercio internacional.

La política monetaria puede ser fundamental como respuesta a las crisis económicas. El lugar central que ocupa la política fiscal en algunos análisis keynesianos debe ser reconsiderado para brindarle una participación más importante al manejo de las tasas de interés como un instrumento poderoso para estimular la producción. 
El caso chileno muestra cómo incluso en momentos en que la política fiscal utilizada es contractiva, al incrementar la recaudación y los ingresos cuando el gasto deficitario se vuelve indispensable, la política monetaria puede tener la suficiente fuerza para reactivar la actividad económica mediante el estímulo al crédito. Las facilidades de financiamiento estimulan la producción y el consumo.

Por ello se vuelve muy importante la defensa de la soberanía monetaria de los países. La creación de uniones monetarias o procesos de dolarización significan la renuncia a un instrumento de política económica de incidencia crucial. En Chile se tuvo que recuperar el control sobre el dinero que circulaba en el país para poder aplicar una política monetaria del corte que se necesitaba para enfrentar la crisis. Se tuvieron que eliminar las restricciones monetarias. Fue hasta ese momento que se dieron los primeros pasos para la recuperación.

Esto no significa que la política monetaria no tenga límites, los cuales deben superarse utilizando medidas alternativas. Las expectativas son fundamentales, por lo que incluso en momentos de crédito barato la producción puede mantenerse estancada si la ganancia esperada no es suficiente para llevar a cabo los procesos de inversión. La capacidad de la política monetaria se reduce de manera considerable en estos momentos. De ahí que no se pueda dar una receta para superar cualquier tipo de crisis. Es en el juego entre la política monetaria y la política fiscal, aunado a otro tipo de medidas y reformas, en donde radica la respuesta más adecuada, siempre en función de las condiciones específicas de cada sistema económico. Lo que se ha demostrado, es que la política monetaria debe ser igualmente considerada dentro de las soluciones posibles. El no hacerlo así significa renunciar a una de las principales herramientas de política económica que los gobiernos tienen a su disposición.

\section{LISTA DE REFERENCIAS}

Banco Central de Chile (1932). Sexta memoria anual presentada a la superintendencia de bancos. Año 1931. Santiago de Chile: Autor.

Banco Central de Chile (1933). Séptima memoria anual presentada a la superintendencia de bancos. Año 1932. Santiago de Chile: Autor.

Barros, E. (1935). How Chile Has Met the Depression. Foreign Affairs, 13(4), 638. DOI: $10.2307 /$ 20020222

Bértola, L.y Ocampo, J. A. (2013). El desarrollo económico de América Latina desde la Independencia. México: Fondo de Cultura Económica.

Braun, J., Braun, M., Briones, I., Díaz, J., Lüders, R. y Wagner, G. (2000). Economía chilena 18101995: Estadísticas históricas. Santiago de Chile: Pontificia Universidad Católica de Chile.

Carrasco, C. (2009). Banco Central de Chile 1925-1964: Una historia institucional. Santiago: Banco Central de Chile.

Collier, S. y Sater, W. F. (2004). A history of Chile, 1808-2002. Cambridge: Cambridge University Press. DOI: $10.1017 / \mathrm{CBO} 9780511991189$

Díaz, C. (1985). América Latina en la depresión, 1929-1939. En M. Gersovitz y W. A. Lewis (eds.), Teoría y experiencia del desarrollo económico: Ensayos en honor de Sir W. Arthur Lewis. México: Fondo de Cultura Económica.

Drake, P. (1984). La misión Kemmerer a Chile: Consejeros norteamericanos, estabilización y endeudamiento, 1925-1932. Cuadernos de Historia, 4, 31-59. 
Drake, P. (1989). The money doctor in the Andes: The Kemmerer missions, 1923-1933. Durham: Duke University Press.

Eichengreen, B. (1996). Golden Fetters. Nueva York: Oxford University Press. DOI: 10.1093/ 0195101138.001 .0001

Kemmerer, E. W. (1926). Chile Returns to the Gold Standard. Journal of Political Economy, 34(3), 265-273. DOI: 10.1086/253762

Kindleberger, C. (1984a). A financial history of Western Europe. Londres: George Allen y Unwin.

Kindleberger, C. (1984b). The 1929 World Depression in Latin America-from the outside. En R. Thorp (ed.), Latin America in the 1930s. The role of the periphery in world crisispp (pp. 315-329). Londres: Palgrave Macmillan.

Llona, A. (1997). Chilean Monetary History, 1860-1925 an Overview. Revista de Historia Económica/Journal of Iberian and Latin American Economic History, 15(1), 125-157. DOI: $10.1017 /$ S0212610900006327

Lüders, R. y Wagner, G. (2003). The Great Depression: A defining moment in Chile's development? Cuadernos de Economía, 40(121), 786-791.

Marfan, M. (1984). Políticas reactivadoras y recesión externa: Chile 1929-1938. Colección de Estudios CIEPLAN, 82, 89-119.

Palma, G. (1988). De una economía de exportación a una economía sustitutiva de importaciones: Chile 1914-1939. En R. Thorp (ed.), América Latina en los años treinta: El papel de la periferia en la crisis mundial (pp. 50-80). México: Fondo de Cultura Económica.

Riveros, L. (2009). La Gran Depresión (1929-1932) en Chile (No. 293). Santiago de Chile: Departamento de Economía, Universidad de Chile.

Seidel, R. N. (1972). American Reformers Abroad: The Kemmerer Missions in South America, 1923-1931. The Journal of Economic History, 32(2), 520-545. DOI: 10.1017/S002205070006 7231

Subercaseaux, G. (1938). Seis años de política monetaria (1933-1938). Santiago de Chile: Sociedad Impresora y Litográfica Universo.

Thorp, R. (ed.). (1984). Introduction. En Latin America in the 1930s. The role of the periphery in world crisispp (pp. 1-16). Londres: Palgrave Macmillan.

Toso, R. y Feller, A. (1983). La crisis económica de la década del treinta en Chile: Lecciones de una experiencia (No. 21). Santiago de Chile: Banco Central de Chile.

Vergara, A. (2015). Los trabajadores chilenos y la Gran Depresión, 1930-1938. En A. Knight y P. Drinot (eds.), La gran depresión en América Latina (pp. 73-108). Mexico: Fondo de Cultura Económica. 